\title{
Geografía Poética de Alberto Hidalgo
}

\author{
El antecedente bélico
}

$4 \mathrm{~N}$ ocasiones sucede que la guerra es creación, aun para 1 aquellos que no la padecen. Alberto Hidalgo no oyó materialmente el retumbar de los cañones, ni cómo la muerte se suspendía del aire o brotaba del agua, pero supo intuir, en su Arequipa natal, todo el valor trágico del tremendo espectáculo. Nacido a la poesía bajo el signo bélico, su temperamento exaltado y batallador, recoge lo más notorio del Futurismo, y con desenfado y audacia, adopta actitud de precursión, viniendo a ser un hito americano en la ruta de "dadá". 1917 alumbra la aparición de un hermoso libro juvenil: Arenga lírica al Kaiser, con el que lanza la sonda al agua turbia de las modalidades literarias de vanguardia, y piloteando la revista Anunciación, va abriendo trocha, por entre la selva tupida del Modernismo, a la renovación profunda del universo poético. Cuando aún se escucha el eco de esta proclama guerrera, Hidalgo se lanza, con ánimo jactancioso, a conquistar a Lima, con actitudes egolátricas y versos de sonoridad acerada. Panoplia lírica presenta a un hombre de gran formato, de imágenes altas y de palabras fuertes, que avienta ideas como olas el mar, que ve la tierra con sensación genésica, y a ella se aproxima con espasmos rudos y sensualidad tremenda.

No creo que en las letras de Indoamérica abunden mensajes de tan recia arrogancia como su "Canto a la guerra": 
Los cañones derrumban las viejas catedrales que han visto tantos años por sus arcos pasar, los recintos del arte, los grandes monumentos, los castillos rodeados por fuentes de cristal, porque los hombres nuevos despreciamos lo antiguo; porque conscientemente queremos dominar sobre las artes viejas, retóricas y rancias, cantando los misterios de la electricidad; por al oir el redoble del tambor del pasado forjamos el Futuro con hacha de titán; porque escribimos versos al Tren y al Automóvil, al poder de la Fuerza y a la Velocidad y porque resolvemos los problemas del alma aprovechando el cálculo infinitesimal.

Esta angustia de creación objetiva, este mensaje de rasigos demoníacos, este elogio a la violencia y al goce temporal, expresa cabalmente el hambre de dominio de su yo íntimo, inflamado y áureo como una llama sin humo. $Y$ este sentirse del tamaño del espacio, trasfundido en la tierra, más grande que todos los seres, no es sino la descarga en la imagen de un exceso de líbido, de un estado de tensión propio del aỉma y de la vida modernas. Por donde a Alberto Hidalgo hay que reconocerle virtudes intuitivas y méritos de calidad, de los que ha de frutecer el proceso artístico subsiguiente. En la cronología americana se adelanta a su época, pero su mérito no está en los valores estéticos entrevistos, sino en que ha sido un plantador de hitos, un individuo de avance, a quien no le gusta demorarse en las cosas. Hidalgo pone a producir el germen y sale en busca de nuevas posibilidades, a abrir nuevos cauces, abandonando demasiado pronto los predios recién sembrados, cuya cosecha ha de ser levantada por otros. De ahí que lo encontremos siempre en los puestos de avanzada, y que si con su nombre se inicia el nuevo camino poético del Perú, también a su nombre habrán de referirse los críticos e historiadores de la literatura, al ubicar la insurgencia estridentista, el movimiento antológico, la teorética del nuevo poema, el simplismo y la génesis de la arenga lírica revolucionaria.

¿Y quién, ahora, hace caso de los sembradores, y quiere que se le den mensajes? ¿Quién hace memoria y se apasiona 
por los echadores de cimientos, que se revuelven de angustia y se conforman agónicamente porque extraen de sí mismos la cara de la fatalidad? Estos lectores del juanramonjimenismo retrasado y la ibarbourumanía bíblica, no conciben, ciertamente, la simple vocación del pionero literario, ni conciben que nadie tome nuevos rumbos cuando aún no comienza a explotar los encontrados. Alberto Hidalgo es de los que se abren camino y luego lo abandonan para trazar ancha vía a nuevas percepciones. Su obra es honda, y por serlo, no obtiene la demanda que debiera en el tianguis de los cachivaches. La fuerza le mana por todos los poros y no en dosis homeopáticas, sino en caudal torrentoso. Sus libros los conforma con sangre, y en ellos compromete demasiado la emoción. Cuanto a. la técnica poemática a que aluden los papelófagos de la crítica, no me interesa. Después de todo, la técnica no es una. dimensión ni un estado tenso. La poesía obtiene talla de su sentido, no de sus procedimientos. "Las voces de colores" y "Joyería", poemas publicados en Buenos Aires en 1918 y 1919, serán a pesar de todo, actitudes poéticas, cada una superada por la subsiguiente, pero bellas dentro de su respectiva órbita, con su sencillez aldeana y su simbolismo a cuestas, su verdad propia y todo lo demás que es alma de cada una.

Lo simple y la verdad poética

Con "Las voces de colores", Alberto Hidalgo ingresa en la verdad sencilla. La verdad, pero, \& es que existe una verdad poética? Atisbos, contornos de la verdad, eso sí: todo buen poeta nos la ofrece fragmentada, y dejaría de serlo si no lo hiciese. Pero la verdad poética en su pureza simple: esa son pocos los que logran aprehenderla. Entre los poetas indoamericanos, es Alberto Hidalgo uno de esos pocos.

¿La verdad poética?, se interroga. Por ejemplo: ¿la de que el poema vale por la música? ¿O que la imagen es la columna vertebral del verso? ¿O que se abstrae el sentimiento en razón de la metáfora? No, por supuesto, no hay que esperar mucho de esas calidades de la poesía. La verdad a que hago referencia es una verosimilitud psíquica. Cuando las vivencias reales contenidas en un poema corresponden en una 
mensura suficiente con nuestras vivencias anímicas, es decir, con expresiones afincadas en un proceso interpretativo del acaecer cotidiano, o que pudo habernos sucedido, decimos, sin temor a dudas: este verso corresponde a una poesía verdadera. Pero esa no es la verdad completa. La expresión de un suceso o de una cosa ocurrido en el mundo o en la trasconciencia, será poéticamente verdadera, en la medida en que las palabras que la integran, sean inespeciosas, exactas en su simple particularidad. La buena poesía posee una verdad superior, es más convincente, más aceptable para el alma que los mismos hechos.

¿De dónde proviene esta aceptación interna? De que el poeta está dotado de un sér sensible, de una facultad comunicativa, de un acarreo conviccional de que están horros los acontecimientos, al igual que la mayoría de individuos a quienes -estos sucesos les acontecen. La verdad poética sólo aprovecha a quienes poseen cualidades receptivas. El poeta es ducho en captaciones y maestro en el sentido de saber trasmitirlas. La vida le deja entre las manos mucho más que al común de las gentes, $y$ puede irradiar lo que ha recibido, con una fuerza penetrante, que infunde en el substrato anímico de sus lectores. De ahí que una de las reacciones primarias ante un buen poema, encuentra expresión en la frase: "Esto lo he sentido o lo he pensado yo, sin que nunca pudiese vaciarlo en palabras, ni aun para mi íntima frruición".

Con esto considero haber sacado de la zona obscura el problema de la verdad poética. Al aplicárselo a Alberto Hidalgo diremos que las experiencias que él inculca en imágenes altas se ajustan con nuestras experiencias afectivas, y el punto de confluencia no se realiza en un sector único, sino en toda la dimensión de los sentidos y del alma.

Eso por lo que atañe a la verdad poética. Alberto Hidalgo sobrepasa ese ámbito y lo transfiere a la verdad de la vida. Oigámosle, si no, en el poema "Ayer":

Hoy, Juan, el campesino de la barba hugoniana, con su visita ha puesto calor en mi alma viuda; yo he sentido el perfume de la aldea lejana al estrechar con fuerza su franca mano ruda. 
He visto aquelios años de mi niñez remota, cuando solía en burro cabalgar y solía el sol de la mañana beberme gota a gota desde los soportales de la casona mía.

He recordado aquella leche al pie de la vaca y he visto como en sueños aquel rato furtivo en que amáronse un cabro y una cabrita flaca y en que yo sentí ganas de ser un poco chivo.

He pensado en aquellas escapadas al huerto $y$ he llorado a raudales por lo que ya no existe. $\mathrm{Y}$ Juan, sin comprenderme, me ha dicho: "Don Alberto, ¿por qué cuando yo vengo se pone usted tan triste?"

Supongamos que somos los protagonistas de esta escena. ¿Cómo reaccionaríamos? Al peso de los recuerdos infantiles que yacen en las aguas turbias del inconsciente, aflorarían imágenes simples al sobrehaz de la conciencia. Después que el campesino nos ha retrotraído a la niñez lejana, esa afloración tomaría la forma de reacciones emotivas, las que a su vez convertiríanse en tristeza. La verdad de la vida, al animarse, trasfundiríase en verdad poética, con lo que el problema ya no será el tema ni su expresión, sino el léxico. Para un tema de tanta sencillez, la forma y los vocablos tendrían que ser simples, pues en él no cabe lo especioso, sino la terminología común, lo que siendo vulgar puede ser receptor de contenidos altos.

Transitando ya por el camino de las cosas simples, a Alberto Hidalgo no le quedaba otra coyuntura que la superación mediante el símbolo, o el aislamiento de la pura poesía de entre la totalidad de las experiencias humanas. "Joyería" es, en este concepto, su primera incursión simbólica: incursión en la que el acento se continúa poniendo en lo externo, con tanta convicción y fuerza, como la empleada más tarde en transferirlo a la angustiada interioridad.

El nuevo cauce lo inaugura Hidalgo con sus obras $T u l i$ bro (1922) y Química del espíritu (1923) en los que surge una voz de ancho contenido anímico. El que entrara en la vida, y aún continúa en son de guerra, en la poesía se va despojando de ropajes, abandona sin violencia lo externo, y poco a poco se va introvirtiendo. La adopción del estridentismo es 
sólo técnica, procedimiento en que vaciar una actitud fagocitada por vivencias profundamente humanas. Ya no es literario lo que vehiculiza el pensamiento, sino lo espiritual. Si en su primer libro Hidalgo entronca con la etapa marinettiana, en los dos a que hacemos referencia, la captación, en el sentido de lo europeo, y procediendo por anticipaciones, ensambla en el "Dadaísmo" francés y el "Ultraísmo" español. Son éstos, libros absolutamente nuevos, que denotan un ansia por interpretar las cosas desde otro ángulo. Poesía anunciadora del predominio del alma, en la que se presiente la sensación de lo que ocurre en la trasconciencia, en el inframundo. En medio del donaire de que hace gala y el ingenio que conforma las imágenes, se capta una sensibilidad artística renovada, que no sólo tiene el mérito de lo oportuno, sino que sabe aunar la emoción con el acierto metafórico.

"Ascensión" define cabalmente este ángulo de su poética:

Como si me quitase un sobretodo, yo me he quitado el cuerpo de mi mismo. ¿Qué harapo repugnante! Cuán a modo de cosa inútil lo arrojé al abismo!

No soy sino esto: un alma!

Si es que la beso con viril exceso, preso de una pasión libidinosa, no es con labios del cuerpo que la beso. La posesión también es una cosa espiritual! Por eso se acuesta el picaflor sobre la rosa.

No soy sino esto: un alma!

Sintiéndose un alma, Alberto Hidalgo se caracteriza como una personalidad, a la que identifica y asocia cualidades intrínsecas. La gravidez del alma llévale a apoyarse en imágenes primarias y conforma el inconsciente. De ahí la adopción de rasgos arcaicos y el carácter simbólico de sus poemas. El influjo de tesis y antítesis se evidencia en el contraste sensualidad y espiritualidad. La expresión propicia a la tesis de la espiritualidad abunda en relaciones de lo que está por debajo de la conciencia, y de la diástole y sístole de la intuición 
sensible, hace que en el poema se comprenda la antítesis sensualidad. La tensión de los contrarios, descargada en la forma poética, inclina la escisión hacia el lado dè alma, y resuelve el problema transformando en arte la vivencia sensible. De "Simplismo" a la arenga lírica revolucionaria.

Siguiendo estos procesos, la nueva senda de Alberto Hidalgo había de manifestarse completamente desenvuelta dentro de las extremas y audaces formas, en 1925, y en el libro Simplismo. Ser simple en poesía, no es evidentemente un predicado real, sino más bien un concepto estético que añadir a un concepto vital. Es sólo la posición de un alma o ciertas determinaciones respecto de la actitud de sí mismo. En el uso poético es únicamente la cópula de lo no mixtificado e indiviso. La proposición: "La poesía es simple" contiene dos conceptos que le tienen por objeto: Poesía y simple. Lo simple no es un predicado que se otorga por añadidura, sino llanamente lo que relaciona a la poesía con sus cualidades —entre las que se cuenta lo simple_-, y si digo: la Poesía es, no puede afirmarse que añada una nueva cualidad al concepto de poesía, sino que enuncio a ésta en sí misma con todos sus predicados, y a éstos en relación con mi concepto. Ambos, la poesía y sus predicados, deben contener exactamente lo mismo, y por lo tanto, nada pueden expresar si no es una posibilidad dentro del reino interior.

El simplismo poético es una dimensión de lo singular, donaire de lo raro, excelencia de lo sin adorno, dominio de lo apacible, de lo inafectado, en el que la palabra tiene poder mágico por sí misma. La acentuación fisonómica se la dan las vivencias interiores, en el simple trasvasar de la emoción, el sentimiento y la imagen. La poesía es químicamente simple. De ahí su actuante e intenso poder sobre la sensibilidad. Toda poesía simple reacciona con rapidez en el inconsciente, pero se muestra tarda para las conexiones lógicas y el instrumental de la razón. Así, la poesía químicamente simple posee poder de convicción acerca de la sensualidad, al afinarla, corrigien. do su estilo, y dotando de nuevas formas a la vida emocional. - Puestos en contacto con la materia poética, las sustancias del Sêr ensamblan, por el momento, en una garbosa y simétrica 
figura, tal como los detritus del hierro se agrupan bajo la atracción del imán. De la lectura de una poesía de índole simplista, se yergue uno con la impresión de hospedarse entre lo indiviso, moviéndose entre esquinas agonales y afecciones que provienen del éxtasis.

Veamos, por ejemplo, "Sepelio simplista", en el que se denota claramente la influencia de la embriaguez etérea:

\author{
El zinc del cielo para el ataúd. \\ Soldadura de lágrimas. \\ La caja construída de recuerdo, \\ la madera mejor para los que se van. \\ El dolor quedó encargado de prestar los clavos \\ para ajustar la tapa. \\ ¡Que la fosa la caven en el aire!
}

El hombre que así se nos presenta está desnudo y a merced del destino. Para ser capaz de proclamar el estoico desasimiento del espíritu, debe poseerse la virtud de levantar la estatura por encima de la corriente de las cosas. Lo racional resulta concepto demasiado angosto para expresar la vida de su integridad. Ahora bien, el suceso irracional canalizado en el poema, quiere decir, psicológicamente, que se ha acuñado una nueva expresión de intensidad vital. El comprobar este hecho puede darnos la talla de un poeta. Poeta auténtico es, no sólo el que expresa lo personal, sino el que se muestra capaz de ir fagocitando la interpretación de lo inconsciente colectivo.

Misión del poeta ha sido en todos los tiempos la de sintonizar las misteriosas corrientes del subsuelo y conformarlas en símbolos y actitudes alegóricas o semióticas. Hoy, más que nunca, está obligado a asumir vocación de vate, es decir, a pronunciarse por medio de vaticinios. Sacando a luz lo que ocurre en el Inconsciente se adquiere virtualidad de profecía, puesto que se expresa lo que con el tiempo ha de insurgir en la sobrehaz como fenómeno de índole general. De verdaderos síntomas de radiografía social pueden calificarse, por ejemplo, "Ubicación de Lenin", "Envergadura del anarquista" y "Biografía de la palabra Revolución", poemas en los que Alberto Hidalgo se anticipa a la poemática revolucionaria de Indo- 
américa. Su intención no fué, ciertamente, la de poner la poesía al servicio de la política, como es la abrigada por quienes vinieron detrás de él, sino la de anticipar soluciones a un conflicto que se vincula a un acto de rebelión cruenta contra la anquilosis de la moral colectiva tradicionalista.

En un poeta de formato mínimo ha de suponerse que el climax de su poesía no sobrepasa el nivel de sus pequeños dolores y deseos personales. Mas en Aiberto Hidalgo el hecho poético rebasa lo meramente personal. Lo que ha hecho aflorar al poema estaba en realidad en el inconsciente colectivo. Por eso sus actitudes emergieron más tarde como fenómeno psicológico de masas. El asesinato de Sánchez Cerro y los otros atentados a presidentes que evidencian una escisión de nuestra época, la verificación de movimientos de contenido revolucionario cada vez más claro y tantos otros fenómenos psicológicos de multitudes han sido expresados rotundamente por la virtud creadora de la poesía.

Sin embargo, lo que Alberto Hidalgo conforma, es únicamente el signo, percibido en goce estético, mas sin ser vinculado conscientemente a su alta significación político-social. De aquî su influencia esencialmente restringida a los medios intelectuales. La masa no le entiende aunque por modo inconsciente viva lo que él expresa. $Y$ no porque él lo vehiculice en formas aceradas y mordientes, sino porque vive inmerso en las zonas de lo colectivo, a las que con agudeza penetra el espíritu creador. Cierto que en actitudes como las expresadas en Descripción del cielo, libro publicado en 1928 -aunque buena parte de sus poemas eran conocidos de tres años atrás-, junto con las avizoraciones y sondajes en el inconsciente colectivo, irrumpe algo de enfermizo, aunque grávido de honda significación. Pero en ambos casos, en la insurgencia revolucionaria y en la aparente irrealidad, hay un fuego de pasión que lo devora todo, abrasándole las ideas y recociéndole la carne, hasta hacerle sentir qué nace de nuevo y cotidianamente en este quemar constante.

Otra de las características de Descripción del cielo, es la voluntad tendida hacia la creación de un poema, en que cada verso de por sí, y separadamente, constituyera otro poema. 
Teoría del nuevo poema

He aquí por donde el poeta irrumpe en la marea de la teorización. Por cierto que en Indoamérica ha faltado la actitud teorética. De entre los valores de la nueva poesía, poco puede extraerse de autoexplicación. Hidalgo, siempre animoso y perspicaz, desde las páginas de Amauta se mantuvo en función de autocrítica, demostrando ser un teorizador sutil, con su invento del "poema de varios lados".

"Llamo yo lado del poema - dice Alberto Hidalgo- a cada uno de los versos que lo forman y alguna vez a los distintos asuntos que contribuyen a darle unidad. En una figura geométrica cualquiera, un lado es una parte del todo, pero un lado es un lado en sí, es decir, es una figura él también, tiene una personalidad, una individualidad exclusiva y aislada, y justamente eso afirma; sostiene la figura. Así por ejemplo, un cuadrado, se le mire del lado que se le mire, es siempre un cuadrado. Cuando un hombre está de pie, es un hombre de pie; cuando está tendido es un hombre tendido; cuando está sentado es un hombre sentado. Nunca, pues, deja de ser hombre. Son distintas sus posiciones, pero su carácter es el mismo. Es porque el hombre está hecho de partes totales, incofundibles entre sí, partes empeñadas en recordarnos a cada instante lo que ellas son, independientemente de lo que juntas llegan a ser. Preguntémosle al cerebro si se quiere cambiar por rodilla y nos responderá rotiundamente que no. De no ser así, veríamos a ciertos escritores poner avisos en los diarios diciendo más o menos: 'Cambio mis cuatro manos por un cerebro'."

El poema, por lo que toca a su exterior, está formado de versos. Un verso en sí es una obra de arte. Y es obra de arte tanto más valiosa cuanto menos deja de serlo al hallarse solo en el desierto de una página. Hay multitud de versos que no lo son sino por la vida que les prestan sus compañeros. Yo pregunto si todo renglón de once sílabas es un verso, por el simple suceso de estar provisto de los "acentos tónicos" de que habla la retórica antigua. Se me dirá seguramente que no. Veámoslo:

La huerta con rosales y repollos. 
No parece, ¿verdad?, que eso sea un verso. Sin embargo, lo es, cuando recibe la ayuda de otros:

Sombra en el corredor y el campo ardiendo.

La huerta con rosales y repollos.

Una gallina pasa, precediendo

los puntos suspensivos de sus pollos.

Esto es un poema. Inmediatamente decimos que es un poema de cuatro versos. O sea que damos calidad de tal al segundo renglón de once sílabas.

He aquí una demostración de que el verso habitual no tiene personalidad propia. El verso es el vehículo de la expresión poética, y no obstante los poetas le conceden en su obra un lugar secundario, $y$, lo que es peor, contingente.

Para subsanar eso, es que yo he inventado el poema de varios lados, poema que puede leerse de arriba a abajo y viceversa, o comenzando del centro, o de donde uno se antoje, poema en el que cada uno de sus versos constituye un sér libre, a pesar de hallarse al servicio de una idea o una emoción centrales.

Al poema corriente y moliente se le llama con bastante acierto una composición; del poema de varios lados se podrá decir que es una construcción.

Como muestra e ilustración de lo que Hidalgo se proponía, consideraremos su "Biografía de la palabra Revolución", inserta en Descripción del cielo:

Palabra que nació en un vómito de sangre.

Palabra que el primero que la dijo se ahogó en ella.

Palabra siempre puesta de pie.

Palabra siempre puesta en marcha.

Palabra contumaz en la modernidad.

Palabra que se pronuncia con los puños.

Palabra grande hasta salirse por los bordes del diccionario.

Palabra de cariño fácil como una curva.

Palabra de cuatro flechas disparadas hacia los puntos cardinales.

Aquí quedó desenraizada de olvido toda su anécdota

sobre uno de los vértices más remotos del tiempo.

Los dolores humanos hicieron campo de concentración

para emprender la ruta. Hacia qué cielo?

Cada uno según su intensidad tomó diverso carácter alfabético 
y la palabra quedó escrita

R E V O L U C I O N.

$Y$ fué el primer aviso luminoso del mundo.

Ahora está en el hombre igual que está el oxígeno en el agua.

Campos, ciudades, mares, cuentan con una población en sus ecos.

Les ha substraído el espacio a los cuerpos que se dilatan.

Tiene violencia y distensión de ola de viento.

Entra en las almas con una sensualidad de arado.

Cartel escrito en el claro de dos brazos erguidos,

alcémoslo con la vida.

Si el "Modernismo" eliminó las formas clásicas como nuncios de verdad poética, las tendencias de vanguardia, superando las cimas de la objetivación de la idea poética, tendieron a subjetivarlas más y más. El fraccionamiento en sectas o células de sectas es la consecuencia extrema de este proceso de subjetivación. Mas apenas tiene lugar este intento de inmersión en el caos, comienza a organizarse la resistencia contra lo meramente amorfo, adviniéndose a la necesidad de forma y de ley. Al sumergirse el alma en la marea poética ha de crear también las formas que la acojan y la expresen. Este proceso es el que tratan de pilotear los antólogos, operando sobre la base de los contenidos inconscientes, llevados a horizontes espirituales lo suficientemente vastos para asir, en esguinces externos y apariencia interna, los problemas cardinales de la poesía de su época.

Alberto Hidalgo, desde Buenos Aires, cumple también con este cometido. En Indice de la nueva poesía hispanoamericana (Antología de vanguardia), afirma los valores intrínsecos de la poética del momento. La obra se realiza en colaboración con Vicente Huidobro y Jorge Luis Borges, y en ella se hospedan - con las limitaciones de todo lo fraguado a la distancia- los más significativos aportes, y se encaran los problemas de la poemática actual, hasta reducirlos a un orden artístico.

La integración del símbolo y el camino hacia la dimensión metafórica

Toda forma poética verdaderamente viva, organiza en el verso esta o la otra tendeneia primigenia, con lo que le aflu- 
yen los socavadores impulsos que dan lugar a la modificación de la textura de la existencia. Este proceso, este continuo establecer conexiones con el trasmundo supone un contacto con las tierras del inconsciente, manaderos de toda energía. En el sentido de toda concepción poética diferenciada estos impulsos son de esencia impura. Mas la psique misma, tal como es, se nutre sincrónicamente de claros y de turbios manantiales. De donde el que la poesía - flor de la psique- no obedece a una "pureza química", pues lo puro extremado está horro de vida.

Toda renovación del acontecer poético ha de pasar por lo turbio en avance hacia lo claro. El proceso de la evolución poética precisa esclarecerse y enturbiarse igualmente. Esto es lo que ha visto certeramente el gran poeta que es Alberto Hidalgo.

Actitud de los años - su antepenúltimo libro-, calificado por Luis Alberto Sánchez como "uno de los testimonios más altos de la lírica americana", es; en virtud de su agudeza de visión interna y por lo elevado de su sentir metafísico, no solamente lo más puro de la poesía, sino lo más decantado de las corrientes turbias advenidas a la claridad.

Del mismo modo en que estos poemas son una personificación de Elvira, su compañera que murió, también representan contenidos inconscientes personificados, siendo la imagen del amor pensado con delicadeza y sentido con vocación simbólica. Hidalgo parece hablarnos sin cesar de la raíz biológica del éxtasis traspuesto al plano espiritual; a lo que acerca es a la configuración primordial de la experiencia "numinosa", no a sus derivados mentales. Lo poético en él está determinado por un amor crecido en las vísceras y que ha concluído identificando a la amada con el alma.

Así han procedido siempre los temperamentos que se mueven dentro de una dimensión metafísica. Ante casos de esta índole, creo que si se pregunta por qué padecemos, por qué sufrimos, por qué nos laceramos, por qué se busca el asidero de lo que nunca muere, no cabe sino contestar: "Para que la poesía pueda nacer en el alma y a su vez el alma engrandecerse en la poesía". Para esto se han escrito libros como Los arca- 
nos de Milosz y Actitud de los años de Hidalgo, para que la poesía pueda nutrirse en el alma y a su vez el alma en la poesía. El más íntimo germen de todo grano quiere decir planta, de toda flor, fruto, de todo gran dolor, renacimiento psíquico de la poesía.

Hay no poco de voluptuosidad en enfrentarse apasionadamente con la muerte. Las palabras que Hidalgo consagra a la compañera arrebatada por el destino, son las más claras, las de textura más tierna, las de concepto más aéreo, al grado de que los términos corrientes se hacen mullidos y sin asideros casi como el musgo de los ríos. Todo adquiere horizontes de misterio y virtudes de canto. Oigámosle en "Tumba de lo que nunca muere":

Al borde de la sombra empieza el canto.

Límite natural que a la grandeza pone cualquier tarde.

$\mathrm{Y}$ las sonrisas brotan en tiempo de manzana.

Pero todavía no es el huerto.

Canto del ala sola y del esfuerzo referido a la pena.

Desprendida del ave, al ala sola.

El ala vive siempre.

Quedó en nido de angustias acunada de viento.

Todo lo tiene el canto del ala.

Qué no lo oye?

Sueño del cielo se traduce.

$\mathrm{Y}$ el espacio es ya chico para su ansia, pero todavía no es el cielo.

No obstante, se habrá de ver un día volar el ala sola. De aplicársele el patrón racional a esta poesía se la encontrará ilógica, pero es que el de la razón es instrumental insuficiente para las cosas del espíritu. Las conexiones lógicas y la vía racional son incapaces de crear la imagen simbólica. El símbolo obedece a leyes de plusvalía psíquica. El camino de la simbolización poética no es otro que el de proyectar las vivencias del trasmundo y del sobremundo en el acaecer futuro. En Actitud de los años como en Dimensión del hombre - su libro subsiguiente-, se simboliza a sí mismo -al hombrey a su amada, adaptándose al sentido íntimo y al acaecimiento eterno, pero no a la realidad inmediata y objetiva. Con ello 
se resta difusión, pues no todos alcanzan a comprenderle. Aunque de difusión no debiera hablarse, puesto que no es calidad de escritor sino de comerciante. Impopular tiene que serlo, cuanto que su lenguaje no es el que comúnmente se habla, sino un lenguaje subjetivo. Poesía es ésta de revelación, no de ratio convincente.

Siendo de esencia simbólica la poesía de Hidalgo, presupone la conjunción del contraste real-irreal, pero es que lo irreal para la vida es lo real conforme el alma o la condicionalidad inconsciente. Partiendo de una realidad física en desasimiento el poeta llega a una evidencia espiritual. Para caracterizar estos estados diré que tienen lugar en una atmósfera de embriaguez por el sueño. Sueño debe interpretarse aquí como visión íntima y apariencia bella del mundo de la psique. Siendo de tal guisa, las imágenes poéticas es preciso tomarlas como referidas al concepto metafísico de la existencia. A ello se llega por la vía irracional, es decir, por un acto inconsciente portentoso, nutrido de sí mismo, sin que el designio razonable deliberado intervenga en su configuración.

La poesía, cuando está condicionada por altas corrientes metafísicas, no puede ser aprehendida razonablemente. La pura razón nunca descenderá a las profundidades de la vida, por lo que la poesía - tallo de la vida profunda - no es mensurable por sus contenidos. Poesía es goce de lo suprasensible, pasión y alegría de lo eterno. Dígalo si no el soneto "Existencia del tiempo-todavía":

Puestas a ser espacio de entremundos.

Resbalada en el límite del día.

Entre horas existida, entre segundos.

Ella es eco del tiempo-todavía.

Pasajera entre cantos errabundos.

Oída en un subplano de armonía.

Repicada en los tonos más profundos.

Es eco de la música en que ardía.

Forma impalpable, sólo luz la nombra. En plena obscuridad refleja sombra.

Eco de llama apenas presentida. 
En su presente ausencia está su huella. $\mathrm{Su}$ eco es la vida muerta dentro de ella. Pero yo soy el eco de su vida.

Aquí las corrientes eróticas se han espiritualizado y la mujer adquiere simbolización de imagen enigmática. Esta hechura inasible, "de tiempo-todavía", es propia del símbolo activo, colocado muy por encima del intelecto crítico y de eficacia persuasiva tan sólo para el sentimiento. Con lo que la poesía adviene en refugio y manantial psíquico de reposo. La posibilidad de permanencia de unidad con la amada que en la poesía se busca, no consiste en la conexión con lo externo del mundo, sino en elevar su presencia a estatura de cosa singular y eternizarla en anticipación de formas abstractas, que son las únicas en que el hombre puede hospedarse en atmósferas de reposo, frente a la fugacidad de los fenómenos y la confusión del mundo.

Lengua de imágenes es la de Alberto Hidalgo. Imágenes que se encienden como una luz, tranquilas, llenas de espíritu. Angustia las mueve y pasión las deja laceradas. La poesía se confunde en ellas y el misterio las mira cara a cara. Vivían dentro del poeta en espera de que un gran dolor las sacase a la superficie. El dolor de la no presencia de Elvira las puso en pie, y sólo son un mensaje en el que se da el alma al mundo. Su purísima emoción poética transita entre adjetivos asépticos. Su lengua privada es de las que se meten por los recovecos de la trasconciencia. Ha sembrado emociones altas en vocablos corrientes. Conmueve con los acentos claros de "Religión de la rosa", y la dulce y áspera sensación bíblica de "Oración completamente colorad.a". Forma, color, imagen son sincrónicas; adentro está el dolor de Hidalgo, como la miel en el nectario. Sus imágenes son engrames de primer orden, fagocitadas en la condensación de innumerables procesos psíquicos, reiterados siempre.. Verticaliza una mitología cardinal en palabras simples:

Olor de ayer en vaso sin paredes ni fondo, en percepción, y el entonces se hace hoy para después, porque el color de la esperanza es rosa. Se viaja en alas de la voz 
dada en letras y oída adentro, donde recién empieza a nacer la palabra, que no es canción, ni aliento, ni idioma, ni juicio, ni propósito, sino entenderse: botón o júbilo del alma.

Paso primero de la rosa.

$\mathrm{Y}$ más adelante añade:

Pobreza de tener el cielo en uno, con cuanto se ha soñado de ángeles y crecido de rezos, no'es pobreza, es fortuna, propiedad y dominio de la ausencia.

Para concluir, en una voz delgada, crecida en las entrañas:

La misma muerte es sinónimo de dicha, recompensa final, puerto del tiempo, ángulo contemplado desde todas las horas, estación de llegada, y de partida, vértice igual al de los vientos, vórtices, solamente rosa.

Estos versos ofrecen la siguiente perspectiva: Hidalgo parte de una conciencia psíquica, en la que ve la visión de una rosa. En el vaso del ayer, es decir, en lo ilimitado del inconsciente, "en lo que no tiene paredes ni fondo", la rosa es símbolo del alma misma. El significado de la amada muerta, se transvena en el alma y se transporta a la rosa. Se trata, ahora, ya no del presente simple, sino del hoy para el después, y más de la atmósfera metafísica que de la Elvira de la realidad. Conclúyese así el desprendimiento poético del alma de la mujer real y su transfusión en el símbolo, su tránsito a encauzarse en la función de una voz "oída adentro". La idea de la riqueza espiritual, del "cielo en uno", expresada por el "dominio de la ausencia", queda así convertida en la anonadación de la muerte, en el punto de partida de la vivencia psíquica, y su integración mística en una "religión de la rosa". Solamente rosa, es decir, solamente espíritu. Esta pura expresión es una imagen arcaica devenida en símbolo. Con dolor y ausencia - sal y vino de superación - redondeó Alberto Hidalgo ese clamor metafísico de Actitud de los años y Dimensión del hombre. Clamor lírico, dramático y humano, que es 
alta expresión contra la baja temperatura del materialismo de nuestro tiempo. Fina espiritualidad del peruano, que tan a hora llega con su puro mensaje; bien llegada sea, porque el integrarla presupone la mejor fórmula posible para un estado de cosas que está adviniendo, o que aún se desconoce, pero que se reclama como existente.

En toda esta poesía -cruzada de símbolos vivos- algo acosa a Alberto Hidalgo desde adentro. Hay en ello una suerte de misteriosa premonición. El zumo conturbado de su sentimiento se alquitara en ámbitos de tragedia. De la zona en que "los soldados aman a las muchachas, y la muerte, de pie, los goza a los soldados en la perpetuidad de un solo instante, con la premeditada lascivia de la bala"; de la esquina final, "punto de partida del presente hacia lo posterior"; de ahí, en donde lenguas de viento se alzan conduciendo el mensaje de la flor; de donde el destino se le interrumpe en "ángulos de duda", el sér, requerido en ardua guerra en la que purga su caudal, mantiénese tenso, con tamaño de misticismo e introspección. Todo en su poesía se organiza superiormente en interioridades. Es la suya la mejor expresión de un orden de cosas conocido sólo relativamente. Su verso, impregnado de presentimientos, como de agua una esponja, y de augurios, como un alga saturada de yodo, deja transparentar conexiones directas y desligadas de lógica. Por algo la lógica de la poesía no la otorga la razón sino el sentimiento.

Una magnitud esencial inconsciente es la que Alberto Hidalgo formula en su poesía. Se siente así, como el emișario de un orden vegetal, con raíces profundas en el suelo fértil, y anticipaciones tomadas de la altura.

Oigámosle en este magnífico soneto:

Soy un árbol; sentado hoy a su sombra

veo caer las horas en el suelo

del sinreloj de impávido desvelo

cuyas cifras se sabe y no se nombra;

A mi pasión cuando el ardor la asombra

le doy esta frescura, este consuelo

de ramas arraigadas en el cielo

y me llizevo yo mismo alguna alfombra. 
De tanta espera es verde cuanto ocurre y mi savia entre pájaros transcurre mientras su orquesta por el aire yerra.

Pies y cabeza, todo me asegura, por la copa, emisario de la altura; por las raíces, afirmado en tierra.

Poesía ésta proveniente del tiempo trágico en que vivimos, cuyo aire inasequible sólo los menos comprenden y alcanzan. En él se ha acuñado una pura exquisitez de alma. La presencia de su amor refinado pasa por los procesos grávidos de sentido incógnito, e ilumina de fulgor tierno, aspectos a la razón inaccesibles. Lo rico en señales, mantiene en Hidalgo, la elocuencia que convence al pensar y al sentir con la virtud de la imagen. Su ahincada brega poética - alta escuela de fervor metafísico- es estimulada tanto por la percepción como por las corrientes intuitivas. Su clima, en ocasiones abrupto, surge de una suprema adquisición espiritual, obligando a mover el sentimiento en los rumbos contrarios más altamente desarrollados, al par que dentro de los más inferiores y primitivos impulsos.

Toda poesía verdadera es una simbolización de la existencia. 'La de Alberto Hidalgo desenvuelve los giros íntimos del sér, y en el fondo de su geografía de símbolos, es comunión y mensaje. Grande poeta es, y el tiempo, que todo lo mesura, indudablemente pondrá fulgores nuevos en su difícil y sonámbulo acento. En férula de claridades interiores se depura su voz dolorosa, y sus libros son testimonio de una hora del tiempo que aspira a prolongarse en una angustiada simplicidad. El espíritu es nuestro. ¿No es claro, Alberto Hidalgo? Su poesía, patrimonio inspirado, acendra vivencias individuales y sangre colectiva. Hay algo de divino en este morir a diario que se columbra en él. Cabe su actitud agonal en los vocablos más simples. A su lengua se le puede aplicar lo que el poeta dijo respecto a Manrique: "Sólo las palabras corrientes son perdurables. Sólo ellas pueden alcanzar toda su edad".

\section{Gilberto González Contreras.}


